\title{
践 New Disease Reports \\ First report of rosemary leaf spot caused by Nigrospora oryzae in Iran
}

\author{
D. Moshrefi Zarandi ${ }^{1 *}$, M.M. Aminaee ${ }^{2}$, A. Sharzei ${ }^{3}$ and S. Rezaee ${ }^{4}$
}

${ }^{1}$ Department of Plant Pathology, College of Agriculture, Marvdasht Branch, Islamic Azad University, Marvdasht, Iran , 73711-13119; ${ }^{2}$ Department of Plant Protection, Agricultural and Natural Resources Research Center of Kerman, P.O. Box 76175-538, Kerman, Iran; ${ }^{3}$ Department of Plant Pathology, Aburaihan Campus, University of Tehran, Tehran, Iran, 33916-53755; ${ }^{4}$ Department of Plant Pathology, College of Agriculture and Natural Resources, Science and Research Branch, Islamic Azad University, P.O. Box 14515-775, Tehran, Iran

*E-mail: delbar.moshrefi@yahoo.com

Received: 13 Sep 2014. Published: 07 Dec 2014. Keywords: Rosmarinus officinalis, Kerman

Rosemary (Rosmarinus officinalis), a herbaceous and perennial plant in the Lamiaceae, is one of the most important ornamental and medicinal plants grown in Iran. In November 2012, leaf spot symptoms were observed during a survey of rosemary fields in Kerman (southeast Iran). Out of the approximately 150 rosemary plants examined, more than $45 \%$ had leaf spots. Samples of infected leaves were surface sterilised with $0.5 \%$ sodium hypochlorite for three minutes, rinsed with sterile distilled water, cultured onto potato dextrose agar (PDA) and incubated at $25^{\circ} \mathrm{C}$ for seven days. Fast growing woolly colonies were isolated, appearing initially white, later grey, and eventually turning black on both sides (Fig. 1a). Four isolates were collected (DMNOC1, DMNOC2, DMNOC3, and DMNOC4) and stored in the local culture collection at the Agricultural and Natural Resources Research Center of Kerman, Iran. Brown to black, spherical to sub-spherical, single celled conidia, ranging from 11.0 to $14.4 \mu \mathrm{m}$ (mean 13.2 $\mu \mathrm{m}, \mathrm{n}=100$ ), were born on hyaline vesicles at the tip of short and rarely branched conidiophores (Fig. 1b). Based on morphological characteristics, the fungus was identified as Nigrospora oryzae (Ellis, 1971).

To demonstrate pathogenicity, inocula were produced from five-to-sevenday-old PDA cultures of $N$. oryzae isolates DMNOC1 and DMNOC3. Conidia were harvested by flooding the surface of the petri dish with $5 \mathrm{ml}$ of sterile distilled, deionised water and gently scraping the surface of the media with an L-shaped glass rod to dislodge the conidia. The concentration was then adjusted to $10^{4}$ conidia/ml using a haemocytometer. Three two-month-old plants were inoculated with each of the individual isolates by spraying the conidial suspension on to the leaves with a handheld sprayer until run-off. In addition, one plant was sprayed only with water as the control. All plants were covered with plastic bags to retain high humidity and kept in a greenhouse at $25-28^{\circ} \mathrm{C}$. After 10 days, leaf spots were observed on all treated plants (Fig. 1c), with no observable differences between isolates. An average of $34 \%$ of the leaves $(n=70)$ of the treated plants showed spots, covering on average $20 \%$ of the leaf surface. Some of the leaves gradually fell off. The control plant showed no symptoms. $N$. oryzae was re-isolated from the spots, thereby confirming Koch's postulate.

This disease on rosemary, caused by $N$. oryzae, is significant because the main importance of rosemary is the leaves and any discoloration or dropping of the leaves will affect the quality and yield. This fungus has been previously reported from Iran on maize (Naderpour, 2004), barley, and Sorghum bicolor cv. 'Speed Feed' (Abbasi \& Aliabadi, 2009). Lezama et al. (2007) reported a Nigrospora sp. on rosemary in Venezuela, but the species was not specified. To the best of our knowledge, this is the first report of $N$. oryzae on rosemary in Iran and perhaps the world.

\section{References}

Abbasi M, Aliabadi F, 2009. The List of Fungi Recorded in Proceedings of 12th to 18th Iranian Plant Protection Congress (1995-2008). Tehran, Iran: Science and Art Publication, 1-276.

Ellis MB, 1971. Dematiaceous Hyphomycetes. Kew, Surrey, UK: CABI Publishing.

Lezama J, Dávila M, Ulacio D, Mondragón A, Castillo MA, 2007. Micoflora Presente en Plantas Medicinales del Estado Lara, Venezuela. Boletim do Centro Investigacao de Biologia (Maracaibo) 41, 350-362.

Nadepour, M, 2004. Mycoflora of Zea mays cv. Sc 704 seed in Moghan. Proceedings of 16th Iranian Plant Protection Congress, 27 August-1 September, Tabriz, Iran, 120. [In Persian, abstract in English.]

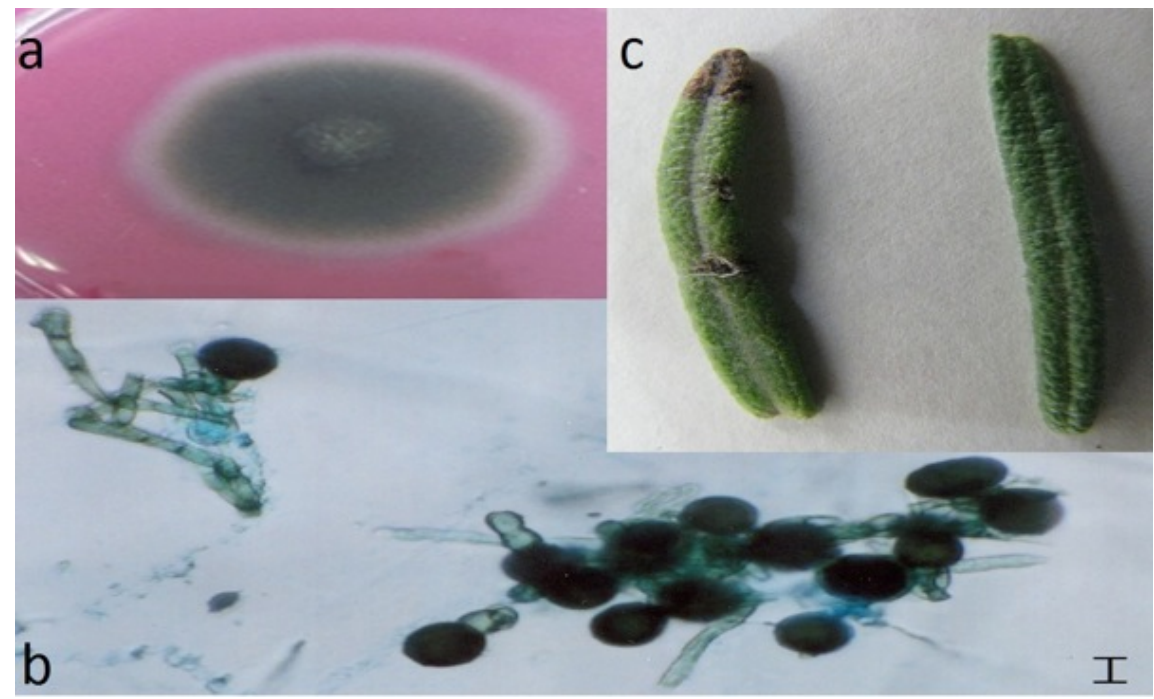

Figure 1

To cite this report: Moshrefi Zarandi D, Aminaee MM, Sharzei A, Rezaee S, 2014. First report of rosemary leaf spot caused by Nigrospora oryzae in Iran. New Disease Reports 30, 27. http://dx.doi.org/10.5197/j.2044-0588.2014.030.027

(c) 2014 The Authors

This report was published on-line at www.ndrs.org.uk where high quality versions of the figures can be found. 